\title{
EFFECTIVENESS ANALYSIS OF WAYS ORGANIZING PRODUCTION OF COMBINED FEEDS
}

\author{
Marina Chkalova, Vladimir Shahov, Victoria Pavlidis \\ Orenburg State Agrarian University, Russia \\ chkalovamv@mail.ru, shahov-v@yandex.ru,pavlidis@mail.ru
}

\begin{abstract}
One of the main trends in the development of the forage industry is the improvement of the organization of production processes that ensure its effective functioning through the introduction of technological innovations. The article is devoted to the development and substantiation of methodology that gives a reliable and consistent assessment of the effectiveness of methods of organizing all technological processes in the structure of production of combined feeds. The authors constructed structural-functional models of technological processes for preparation of combined fodders, implementing the basic principles of production organization. The apparatus of the theory of graphs, as a modeling tool, made it possible to apply effective algorithms for decomposing complex technological processes of feed production and thereby structure them on an abstract level for solving a number of practical problems. Each of the basic methods of production organization has been put in accordance with the oriented graphs, the arcs of which establish factor relationships in the groups of advantages and disadvantages of these methods. The study and analysis of such root structures, corresponding to all basic schemes, facilitated the development of computational formulas for the calculation of quantitative and qualitative indicators of the efficiency of the methods of organizing technological processes in the structure of production of combined feeds. The quantitative index is a generalized summary index of efficiency, a factor of factor efficiency gives a qualitative estimate. The cumulative use of indicators led to the creation of an accessible methodology for assessing the effectiveness of the organization of technological processes, which was tested in conditions of a really functioning feed mill production and proved its effectiveness.
\end{abstract}

Key words: mixed feed, root structures, efficiency indicators.

\section{Introduction}

The improvement of the technological processes for production of combined feeds is one of the directions for solving the problem of obtaining high quality forage, the relevance of which is beyond doubt [1-3]. The qualitative and quantitative parameters of livestock production are largely determined by the effectiveness of the organization of technological processes for the production of feed and innovative methods to improve their basic characteristics. At the present stage of development of the feed industry, technical and technological solutions that realize the concept of resource saving [1-5] become an urgent need. The object of our research is the system of technological processes of industrial production of combined feeds.

The subject of the study and analysis is the optimization of the organizational and technological structure of feed production. The purpose of the study is to develop scientific and methodological foundations for determining the effectiveness of ways to organize technological processes in the structure of production of combined feeds. Necessity of achieving the goal determined the following tasks: to carry out a comparative analysis of technological schemes for the production of combined feeds using the algorithm of using the basic principles of its organization; to build structural and functional models of all technological schemes for the production of combined feeds; to establish qualitative and quantitative indicators of functioning of the constructed models; to develop a methodology for assessing the efficiency of functioning of the technological schemes for the production of combined fodder.

\section{Materials and methods}

At the present stage of the industry development several basic principles of the organization of the technological process of preparation of combined fodders are used [6-8]. Since the middle of the last century, the classical principle has become most widespread. It is based on one-time batching of components, which are prepared preliminarily and separately on sequentially-parallel processing lines, then placed in over-batch silos.

The structure of organization of the process of preparation of mixed fodders can be represented by a marked graph. In the case of implementing the classical principle of organizing the technological 
process, the marked graph has the form shown in Fig. 1. The principle of repeated dosing is based on the formation of preliminary mixtures of certain types of raw materials, each of which is prepared on its technological line (Fig. 2).

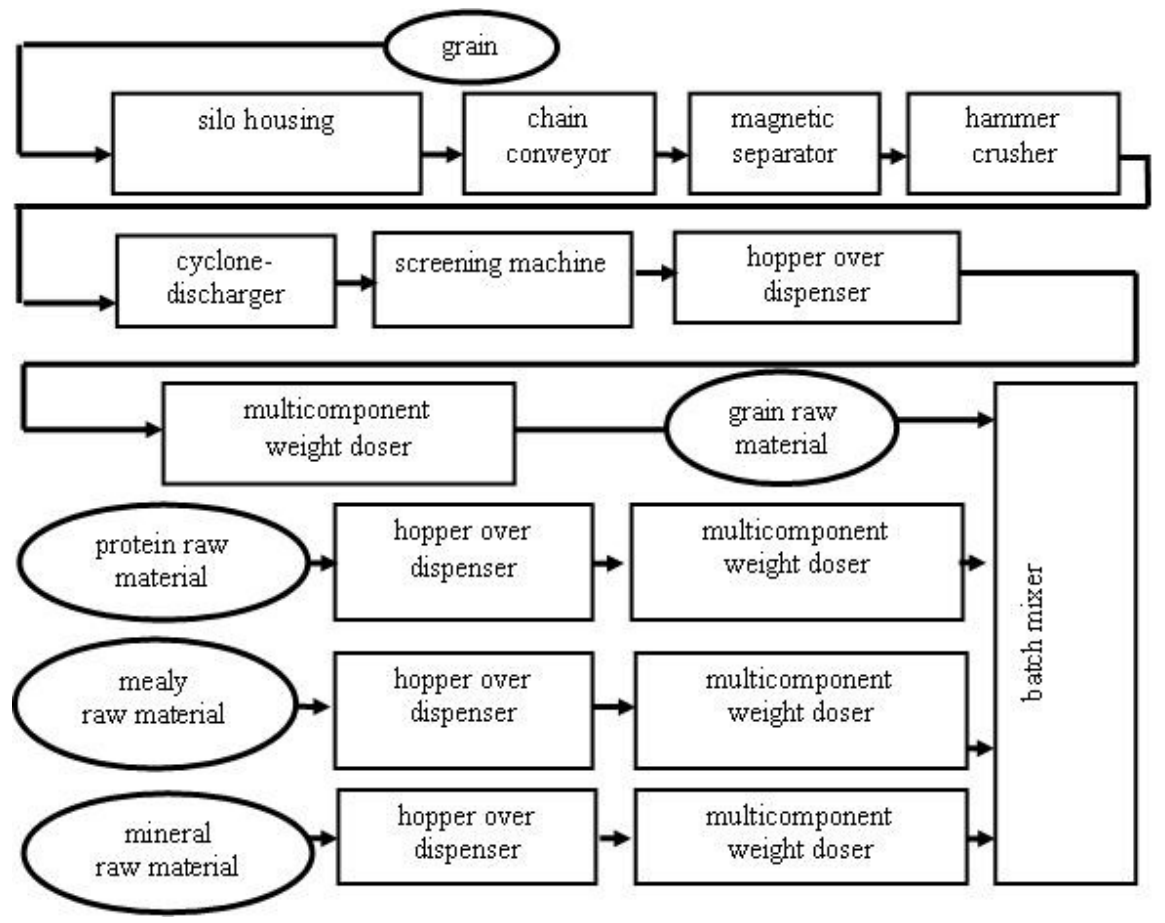

Fig. 1. Marked graph of lassical method

Formation of preliminary mixtures of grain and protein-mineral raw materials is possible without repeated dosing, in strict accordance with the actual capacity of the main mixer, i.e. portion wise. This requires the presence of an operational small-capacity bunker (2-3 tons).

In the case of realization of the principle of formation of preliminary mixtures without repeated dosing, the structure of organization of the technological process is determined by the marked graph in Fig. 3. The organization of the technological process of preparation of mixed fodders, realizing the principle of directness, allows all components of the mixture to be dosed and processed in a single technological stream, up to the production of a portion of finished products. Its structure is represented in the form of a marked graph in Fig. 4. With this method of organizing the production of animal feed there is a need to place the process equipment in high-rise buildings vertically from top to bottom.

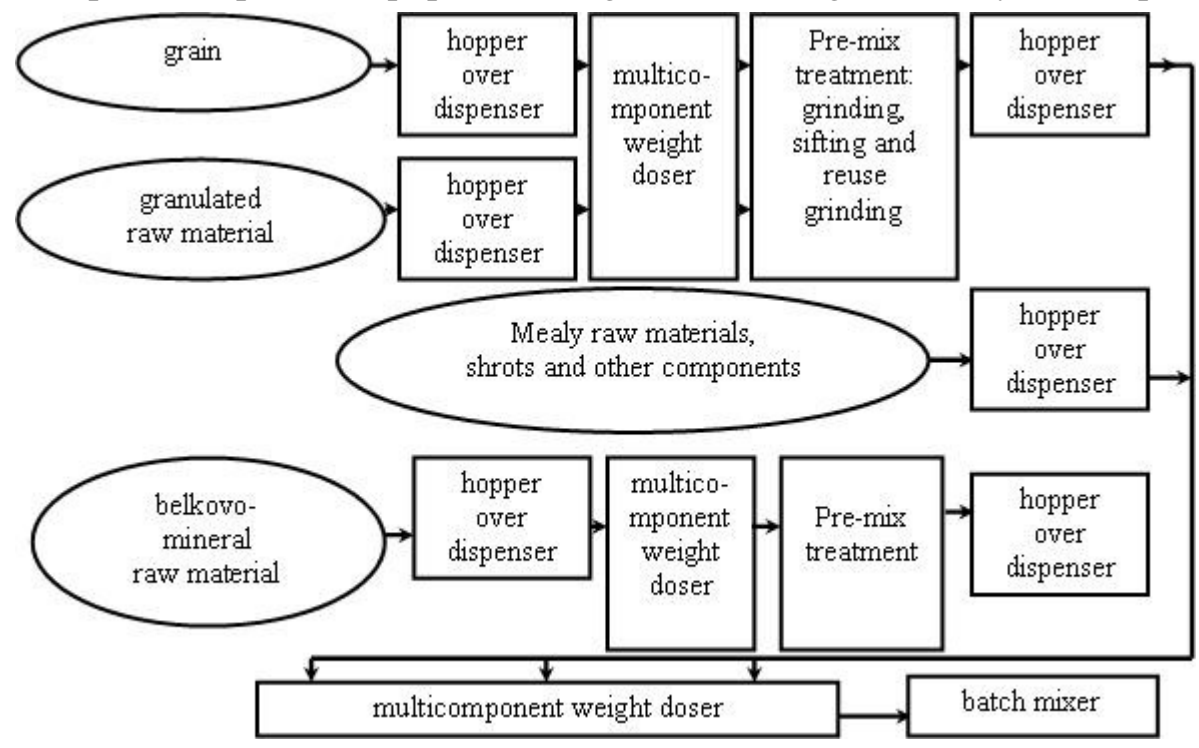

Fig. 2. Marked graph of method of forming preliminary mixture with repeated dosing 


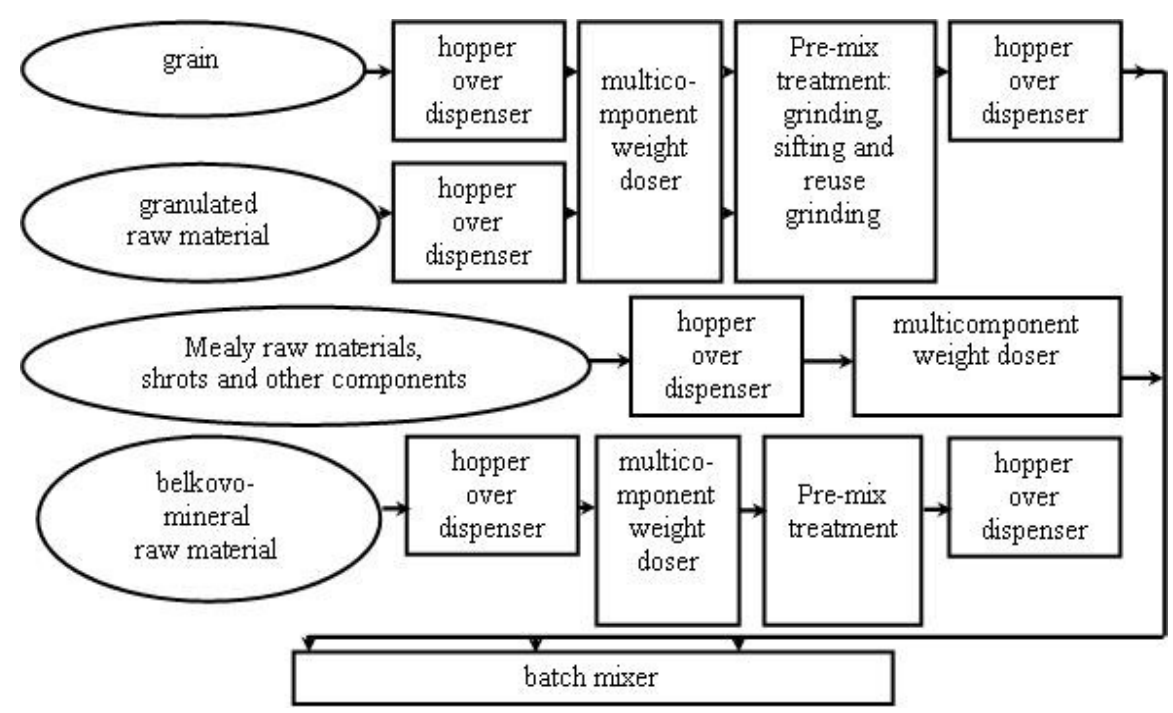

Fig. 3. Marked graph of method for forming preliminary mixture without second dosing

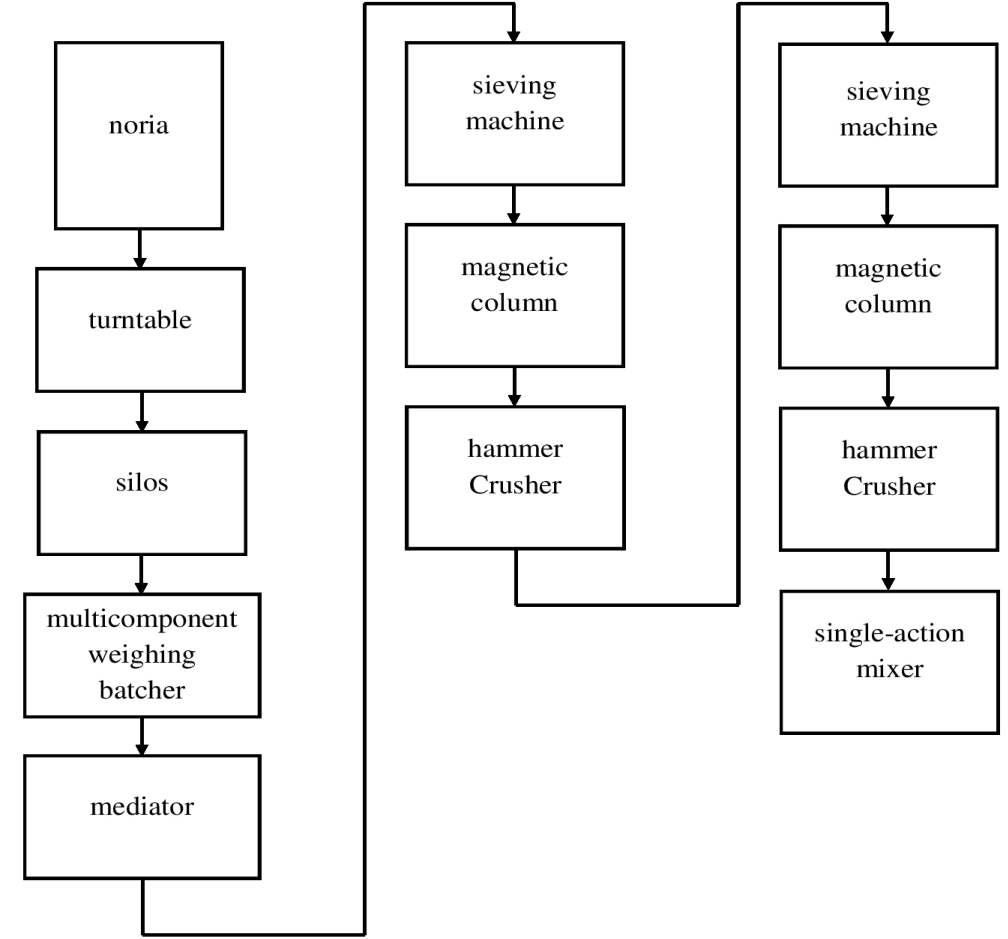

Fig. 4. Marked graph of ramjet method

\section{Results and discussion}

Analysis of the principles of organization of the technological process for the production of combined feeds has made it possible to determine all possible advantages and disadvantages of each of them [9]. The analysis made it possible to develop structural and functional models of all technological schemes for the production of combined feeds, depending on the basic principles of the organization of the technological process [10-12].

As a modeling tool, the apparatus of graph theory is used, because graph analytical methods make it possible to isolate essential elements, to identify the existing links and to justify their hierarchy [1214]. The apparatus of graph theory allows us to offer fairly simple and effective algorithms for decomposing complex technological processes into simpler ones and thereby solve the problems of logical structuring of the organization of processes at the abstract level [14;15]. The main characteristics of the basic principles of the organization are considered as vertices of oriented graphs 
[9], with the dignity noted with the sign (+), the shortcomings by the sign (-). Arcs of oriented graphs are determined by synergistic relationships within the group of "positive" or "negative" characteristics.

An estimate of the position of each vertex in the graph, which determines its place in the general system of attractive resources, the evaluation of the graph as a whole and its parametrization, is carried out by the help of topological measures. These measures are determined on the set of relations between the elements of the graph (vertices, arcs). For each method of organizing the technological process of preparing combined feeds, which is based on the basic principle, we construct two oriented graphs, which we call root structures (Fig. 5-8).

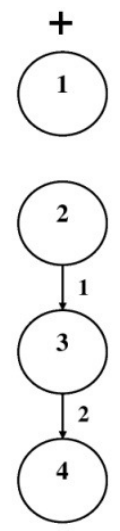

Fig. 5. Root structures of classical method

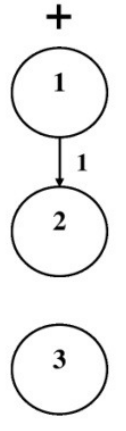

Fig. 6. Root structures of method of forming preliminary mixture with repeated dosing

The numbering of the vertices corresponds to the sequence of the arrangement of the factors in the table [9], the arcs are established on the basis of the factor analysis carried out and show the causeeffect relationships. The numbering of arcs is arbitrary.

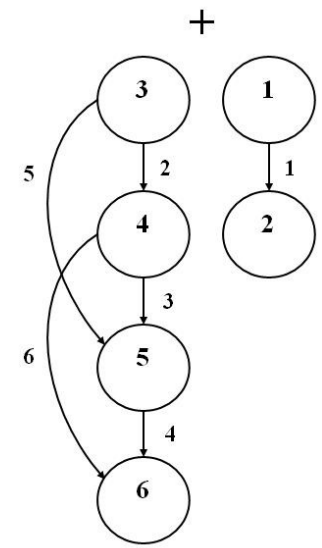

Fig. 7. Root structures of method for forming pre-mix without repeated dosing
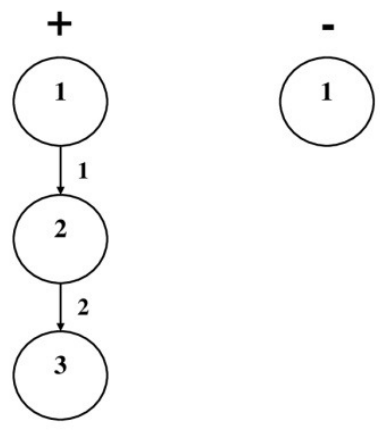

Fig. 8. Root structures of direct-exact method

To assess the effectiveness of organization of the technological process of preparation of combined feeds, determined by the predominance of a positive synergistic effect over the negative, we introduce the quantitative and qualitative characteristics of structural-functional models obtained on the basis of topological measures of the corresponding graphs [15-17]. Summarizing the number of vertices (characteristics) and the number of arcs (links) in each root structure, we obtain its intermediate index Ind and the generalized summary efficiency index $\mathbf{S}$ for each method, which gives a quantitative estimate of the efficiency of the corresponding model. Qualitative evaluation of the efficiency (coefficient of factor efficiency Kef) of the constructed models is obtained as the ratio of the number of positive characteristics to the total number of characteristics. 
The results of calculating intermediate indices, total efficiency indices and factors of factor efficiency, giving a quantitative and qualitative assessment of structural and functional models, are presented in Table 1. Calculation of the generalized summary efficiency index S, which takes into account, in addition to the characteristics, also the interrelations between them, allows us to determine the two most promising ways to organize the technological process for the production of combined feeds: the formation of preliminary mixtures without repeated dosing and the straight-through method.

It should be noted that the combination of these methods significantly increases the efficiency of organizing the technological process for the production of combined feeds:

$$
\mathbf{S}=(12+5)-(-3-1)=17-4=\mathbf{1 3} \text {. }
$$

The obtained result is confirmed by the calculation of the corresponding coefficient of factor efficiency, which gives a qualitative assessment of the structural-functional models used Kef $=\mathbf{0 . 7 5}$, which can be interpreted as the efficiency of the model.

Table 1

Indices and coefficients of structural-functional models of basic technological schemes for production of combined feeds

\begin{tabular}{|c|c|c|c|c|}
\hline $\begin{array}{l}\text { Principles of } \\
\text { organization }\end{array}$ & $\begin{array}{l}\text { Intermediate index } \\
\text { Ind(+) }\end{array}$ & $\begin{array}{l}\text { Intermediate index } \\
\text { Ind(-) }\end{array}$ & $\begin{array}{c}\text { Generalized } \\
\text { total } \mathbf{S} \\
\text { efficiency index } \\
\end{array}$ & $\begin{array}{c}\text { Coefficient of } \\
\text { factor efficiency } \\
\text { Kef }\end{array}$ \\
\hline Classical & $\operatorname{Ind}(+)=4+2=6$ & Ind(-) $=-6-5=-11$ & $\mathbf{S}=6-11=-5$ & Kef $=4 / 10=0.4$ \\
\hline $\begin{array}{l}\text { Formation } \\
\text { of } \\
\text { preliminary } \\
\text { mixtures } \\
\text { with } \\
\text { repeated } \\
\text { dosing }\end{array}$ & $\operatorname{Ind}(+)=3+1=4$ & $\operatorname{Ind}(-)=-2-0=-2$ & $\mathbf{S}=4-2=2$ & Kef $=3 / 5=0.6$ \\
\hline $\begin{array}{l}\text { Formation } \\
\text { of } \\
\text { preliminary } \\
\text { mixtures } \\
\text { without } \\
\text { repeated } \\
\text { dosing }\end{array}$ & $\operatorname{Ind}(+)=6+6=12$ & $\operatorname{Ind}(-)=-2-1=-3$ & $\mathbf{S}=12-3=9$ & Kef $=6 / 8=0.75$ \\
\hline $\begin{array}{l}\text { Straight- } \\
\text { flow }\end{array}$ & $\operatorname{Ind}(+)=3+2=5$ & $\operatorname{Ind}(-)=-1$ & $\mathbf{S}=5-1=4$ & Kef $=3 / 4=0.75$ \\
\hline
\end{tabular}

The cumulative application of the generalized summary index of efficiency and the coefficient of factor efficiency provides an accessible and consistent methodology for calculating the effectiveness of the organization of technological processes in the structure of production of combi-feeds, taking into account the specifics of the subject area.

The proposed methodology was applied to the analysis of organizational and technological processes at the leading enterprise of the feed industry in the Orenburg region of the JSC "Orenburg Mixed Feed Plant" (RF). Before the reconstruction of 2010-2012 technological schemes for the production of combined feeds were based on the use of the classical basic principle in combination with direct flow. After complete technical re-equipment of production and introduction of innovative technologies, a transition was made to a combined method of organization of the technological process: direct flow with the formation of preliminary mixtures without repeated dosing. Changes in the total index and coefficient of factor efficiency indicate an increase in the efficiency of the organization of the technological process, which is reflected in the results of the company's financial and production activities [18-21]. As a result of the conducted studies, the authors succeeded in developing and substantiating a methodology for assessing the effectiveness of methods for organizing technological processes in the structure of production of combined feeds. 


\section{Conclusions}

The theoretical basis of this technique is the structural and functional models that determine the root structures of the ways of organizing various technological processes. The analysis of the constructed models made it possible to establish their basic characteristics and develop computational formulas for generalized indices and factor coefficients, which give a quantitative and qualitative assessment of the efficiency of the organization of technological processes. The verification of the constructed models and implementation of the developed methodology make it possible to consider the obtained results as reliable. The results can be used to optimize the organizational structure of various systems of technological processes based on expert evaluation of the principles of their operation.

\section{References}

[1] State program for the development of agriculture and regulation of markets for agricultural products, raw materials and food for 2013-2020. Collection of legislation of the Russian Federation, 2012, № 30.

[2] Kosolapov V.M.,Trofimov I.A. Importance of fodder production in agriculture. Zernobobovye and cereal crops. Scientific journal, 2013, № 2, pp. 59-63.

[3] Lobacheva T. I. State and directions of the development of the forage base of livestock breeding. Kormoproizvodstvo. Scientific journal, 2017, No. 8, pp.3-9.

[4] Nazarov A.A., Suslov S.A. The current state of the feed industry. Vesting NGIER. Scientific journal, 2013, No.11 (30), pp. 66-70.

[5] Eskhozhin D. Z., Nukeshev S. O., Capov S. N. [et al.]. A theoretical substantiation of a grain cleaner with. International Journal of Environmental and Science Education, 2016, No. 18, vol. 11., pp. 11385-11392

[6] Chkalova M.V., Shakhov V.A., Burlutsky E.M., Pavlidis V.D. Determination of the quantitative parameters of the air-product layer in the working chamber of a shredder. Achievements of science and technology of the agroindustrial complex. Scientific journal, 2017, No.12, pp. 57-60.

[7] Gritsenko G.M., Svintsev D.I. Prerequisites for improving the strategic management of grainprocessing enterprises that have mixed fodder production. Fundamental research. Scientific journal, 2015, No. 10 (part 2), pp.362-365.

[8] Norms of technological design of enterprises for the production of mixed fodders. [online][21.06.2018] Available at: http://www.infosait.ru/norma_doc/39/39261/index.htm. (In Russian)

[9] Chkalova M.V., Shakhov V.A., Burlutsky E.M. Some aspects of the functioning of production lines for the production of mixed fodders by the example of enterprises of the Orenburg region. Improvement of engineering and technical support of production processes and technological systems: Sat.sci.tr.-Orenburg,2018.

[10] Bogatyrev A.N., Lituev V.N. The current state and development of the Russian agribusiness sector (experience of mathematical and probabilistic modeling). Storage and processing of agricultural raw materials. Scientific journal, 2016, No. 6 (part 1).

[11]Bogatyrev A.N., Lituev V.N. The current state and development of the Russian agribusiness sector (experience of mathematical and probabilistic modeling). Storage and processing of agricultural raw materials. Scientific journal, 2016, No. 7 (part 2).

[12] Pavlidis V.D., Chkalova M. V. Mathematical modeling of technological processes in agricultural production. Kormoproizvodstvo. Scientific journal, 2008,No.10.

[13] Geida A.S., Lysenko I. V. Varying the availability of engineering system in the course of its main-tenance. Engineering Simulation,1993, Vol. 11, no.2,pp.317-323.

[14] McKay B. D., Piperno A. Practical graph isomorphism, II. Journal of Symbolic Computation, 2014, Vol. 60, pp.94-112.

[15] Basu A., Blanning, R.W. Metagraphs and Their Applications. Integrated Series in Information Systems, Springer, 2007, Vol. 15, No. VIII, p. 172.

[16] Frank Dr., Berthold H. Detlef Plump Hierarchical Graph Transformation. Journal of Computer and System Sciences, 2002, Vol. 64, No.2, pp.249-283.

[17] Harel D. On visual formalisms. Communications of the ACM, 1988, Vol.31, No.5, p.514. 
[18] Nagano, Seido M. Innovation management processes, their internal organizational elements and contextual factors. Journal of Engineering and Technology Management, 2014, No.33, pp.63-93.

[19] Lukina E.V. Financial results of agribusinesses: the calculation procedure, influencing factors and assessment methods. Achievements of science and technology APK,-2017.-№ 2, p.81.

[20] Accounting (financial) statements of JSC "Orenburg Mixed Feed Plant" [online][22.04.2019] Available at: https://www.rusprofile.ru/id/536124. (In Russian)

[21] JSC “Orenburg feed mill” [online][22.12.2018] Available at: http://orenkz.ru. (In Russian) 